\title{
Mobile Technologies Supporting Professional Learning Communities within Pre-Service Teacher STEM Education
}

\author{
Duncan Symons, Christine Redman \& Jo Blannin \\ Melbourne Graduate School of Education, The University of Melbourne, Australia \\ Duncan.symons@unimelb.edu.au
}

\begin{abstract}
Over a three-year period, academics from the Melbourne Graduate School of Education, The University of Melbourne, have partnered with a range of academics to facilitate an elective subject for pre-service teachers (PSTs).. These academics include staff from the Faculty of Science (The University of Melbourne), the Victorian Space Science Education Centre (VSSEC) and the Gene Technology Access Centre (GTAC) Together we have sought to develop and strengthen their teaching in the area of STEM (Science, Technology, Engineering and Mathematics) education. Students in this subject were supported to develop $21^{\text {st }}$ century skills that enabled them to work effectively in Professional Learning Communities (PLCs). Pre-service teachers observed and responded to each other's teaching providing real time feedback using 'Padlet' (a readily available web based application). Following each lesson students used the resultant 'Padlet' data as a prompt to promote reflective discussion. We analyse excerpts of Pre-service teacher responses to an online survey as a means to gain some understanding of their perception of working in this way. Additionally, Padlet feedback was thematically analysed in an effort to understand how teacher candidates focussed their feedback and limitations of this approach to facilitating professional development. Through adoption of this tool, critical collaborative reflection was fostered.
\end{abstract}

Keywords. STEM Education, pre-service Teachers, CSCL, Professional Learning Communities

\section{Introduction}

STEM education has been receiving increasing attention over recent years. It is seen to offer the potential to enhance development of various 'soft' skills'; sometimes known as $21^{\text {st }}$ century skills [1]. These skills include, but are not limited to, creativity, innovation, critical thinking, decision making, problem solving, metacognition, collaboration and communication.

STEM education is claimed to present a solution to preparing young people for jobs of the future. The Chief Scientist's Office of Australia reports that there is a growing demand for STEM qualified employees [2].

Additionally, STEM education is seen as a potential approach to reversing high levels of disengagement with science and mathematics. Disengagement with these areas is reported to begin in primary school $[3,4]$. 
With the promise of STEM education as a rationale, academics within the University of Melbourne's, Melbourne Graduate School of Education, working alongside academics and scientists from the Faculty of Science, the Gene Technology Access Centre (GTAC), the Victorian Space Science Education Centre (VSSEC) and the Melbourne Museum, have planned and facilitated an elective subject with preservice teacher education students (PSTs) with an integrated approach to STEM education as a focus. The facilitation of the elective subject has been funded through the Reconceptualising Maths and Science Teacher Education Programs (ReMSTEP); an Australian Government program funded through the Office for Learning and Teaching (OLT).

Throughout the three years in which the elective subject has operated, academics working within the subject have been interested in helping students to develop Professional Learning Communities (PLCs) within their STEM planning and teaching. The context for the subject seemed ideally suited to the facilitation of PLCs given that teams of PSTs collaboratively teach each classroom of school children. A key component of the PLCs is an opportunity for students to observe each other teach and provide peer feedback. Whilst observing each other teach, PSTs utilised their mobile devices to record their observations on 'Padlet'; an online, virtual 'wall' that allows individuals to express their thoughts on a common topic easily and collaboratively. In this study, we have coded and analysed the feedback provided within the Padlets to gain an understanding of where and how PSTs directed their peer feedback when working in PLCs.

An additional source of data utilised within this study, were a series of three open ended online surveys. These surveys provided further insight into how PSTs viewed the process of engaging in PLCs and providing and receiving peer feedback.

We aim to address two research questions in this paper:

1. How do PSTs perceive peer observation and feedback, when utilising online mobile technologies?

2. How do PSTs focus their peer feedback when utilising online mobile technologies?

In the following sections, we will first provide some discussion of literature in the area of tertiary level peer learning and the use of online mobile technologies to facilitate Computer Supported Collaborative Learning (CSCL). Next, we will provide some discussion of the Context and Study Design. A discussion of the Results will then occur and lastly some Conclusions and Implications will be offered.

\section{Literature Review}

This literature review is divided into two sub-sections (2.1 and 2.2). Sub-section 2.2 provides background and discussion of literature supporting the first research question, whilst 2.1 provides discussion of literature closely aligned with the second research question. Where possible the literature selected is based within a context of research in tertiary settings. 


\subsection{Peer Observation, Peer Learning and Professional Learning Communities}

Whilst there is some variation in conceptions of what constitutes a PLC, Stoll, Bolam, McMahon, Wallace and Thomas [5] state that "there appears to be broad international consensus that it (PLCs) suggests a group of people sharing and critically interrogating their practice in an ongoing, reflective, collaborative, inclusive, learningoriented, growth-promoting way"[5]. The establishment and facilitation of a PLC can take many forms. However, a common component of PLCs is peer learning; regularly including peer observation and peer feedback. In the context of our study peer observation and feedback was central to the development of PLCs.

'reciprocal peer learning' which includes 'peer observation', has been described as "mutually beneficial and involves the sharing of knowledge, ideas and experience between the participants. It can be described as a way of moving beyond independent to interdependent or mutual learning" [6].

Martin and Double [7] describe the benefits of this approach in staff professional development as follows:

1. improve and develop an understanding of personal approaches to curriculum delivery;

2. enhance and extend teaching techniques and styles of presentation through collaboration;

3. engage in and refine interpersonal skills through the exchange of insights relating to the review of a specific teaching performance;

4. expand personal skills of evaluation and self-appraisal;

5. to develop and refine curriculum planning skills in collaboration with a colleague; and

6. identify areas of subject understanding and teaching activity which have a particular merit or are in need of further development.

In the majority of literature exploring peer learning and peer observation there is agreement that feedback and observation should occur in a non-judgmental, objective and supportive manner [6-8].

Critiques of the approach however, contend that the goal of peer observation is easily subverted. Shortland [9], utilizes Derridean Deconstruction [10] to gain insight into how university documentation relating to the peer observation process can highlight issues of power imbalance between the observer and observees. Deconstruction is described by Chaffee [11] as "a way of rereading texts to uncover the silences in the history of philosophical and social thought and, as he (Derrida) acknowledges, to create silences of its own.” Shortland [9] contends that the observer involuntarily, is placed in a more powerful position than the observee. Additionally, she argues that peer observation is used, at times, as a method of surveillance and used to ensure compliance by figures of authority or management. She states, "discussions revealed some staff members completing observation documentation simply to comply with the managerial requirements to do so, having not actually undertaken the observation process. A mechanism by teaching staff to highlight their perceived needs whilst minimizing their workload or an opportunity for resistance whilst not misbehaving?” [9]. 
With these critiques of peer observation in tertiary level education in mind, we aim to gain an understanding of PST perceptions of the process in our STEM education focused elective subject.

\subsection{Mobile Technologies Enabling Computer Supported Collaborative Learning (CSCL)}

Whilst there in an increasing volume of literature addressing the use of mobile devices, typically mobile/ smart phones, tablets or in some cases lap tops, in teaching and learning contexts [12-14], little research exists specifically investigating the use of internet connected mobile devices to engage in collaborative, observational, feedback of peers within teacher preparation courses.

Symons, Pierce and Redman [15] describe Computer Supported Collaborative Learning (CSCL) as taking "place via the vehicle of technology (computers, tablets, mobile phones etc) typically linked via an intranet or the internet”. Dillenbourg [16] has explained previously, that in order for CSCL to occur, peers who are more or less at the same level, perform the same action, have a common goal, and work together.

The utilization of technology reported in this study, suggests an alignment with Dillenbourg's (1999) description of CSCL. PSTs, who are at the same level, performed the same action of engaging in the planning and teaching of STEM. They had the common goal of furthering the development of their practice and they did so in collaboration with each other and as such were 'working together'. Synergies between the conditions required for CSCL to occur and the collaborative, nonjudgmental, shared support and accountability required of PLCs suggests that taking a CSCL based approach to the use of technology within PLCs is a natural and logical fit. We regard the use of mobile technologies reported in this study as an example of CSCL.

\section{Context \& Study Design}

As a part of a STEM elective subject, which is undertaken in the final semester of their two year graduate Masters level degree, PSTs were required to teach a series of sequential lessons to primary school students taking an integrated STEM based approach. Across the three years in which the elective subject has taken place PSTs have worked with a number of schools in the inner suburbs of Melbourne, across an age range encompassing all of the primary years.

Before teaching within schools, PSTs have had opportunities to develop an ability to work effectively in PLCs through attendance at lectures and engaging in workshop activities designed to enable them to understand the different approaches that may be taken to establishing successful PLCs. For example, in addition to attending a lecture providing more general information about PLCs, PSTs also attended a lecture (from an international expert in the area) providing detailed information about Japanese Lesson Study [17]. They were then asked to draw links and synthesize the various materials.

Following, workshops and lectures, PSTs taught a sequential series of 4 weekly lessons to year 5/6 students (age 10 - 13). The data reported here is taken from a year in which the focus for teaching was on Bees and Bee adaptations. Specifically, PSTs 
were to facilitate a student inquiry investigating, why there has been a dramatic decrease in bee populations over recent years.

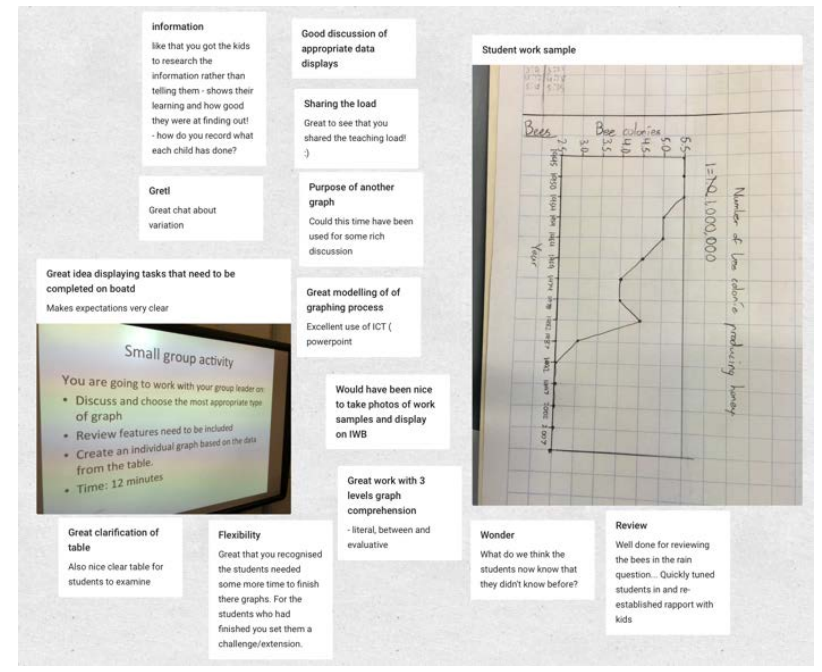

Fig. 1. Section of Example Padlet

During the teaching of each of the four lessons a group would observe the teaching group and use their mobile devices to post short pieces of feedback related to the lesson that they were witnessing on 'Padlet'. At the conclusion of the lessons, each week, each of the Padlets would be displayed on a data projector and the group that had observed the teaching group would facilitate a discussion providing feedback about the teaching group's lesson. An example Padlet is provided in Figure 1. In the example, we see the ability users have to upload multimedia, and provide real-time succinct feedback. Additionally, some understanding of the variety of feedback provided is available. Notably, some feedback focuses on mathematical understandings, whilst some is focused on pedagogical, technical and organizational matters.

Across the four weeks, each contribution, on each Padlet was coded and then aggregated in an effort to better understand on where the PSTs' feedback was focused. Codes allocated to contributions were, 'Science', 'Technology', 'Engineering', 'Mathematics', 'STEM' (indicating a contribution where concepts are integrated across the disciplines) and 'General Pedagogy'.

In addition, to data derived from Padlet we utilize qualitative data from 3, online, open ended, anonymous surveys to gain an understanding of how PSTs perceived their experience of working within a mobile technology supported PLC.

\section{Results and Discussion}

The results and discussion are divided into two sub-sections. Sub-section 4.1 provides a number of excerpts of responses to an online survey that was completed by PSTs within the elective. Analysis of these excerpts provides some indication of how PSTs 
perceived the technology supported peer observation process that was core to the subject. Sub-section 4.1 provides the results of aggregated student peer feedback taken from Padlet and some discussion of how these results suggest that PSTs focused their feedback.

\subsection{PST Perceptions of Mobile Technology Supported peer observation Process}

When asked about their perceptions of working within mobile technology supported PLCs and being part of the peer observation process, PSTs reported the following:

1. I learnt how to successfully collaborate as a team and gained loads of exciting ideas and ways to support and encourage learning in my classroom.

In excerpt 1 the PST suggests that the process of engaging in a mobile technology supported PLC enhanced understandings of how best to collaborate. She emphasizes that she gained new ideas about creative approaches to teaching that she may not have had had access to if taking another approach to learning.

2. I was really interested to see how others use the 5E framework and pedagogical tools in different ways. I am always really interested when people do things in ways I never thought of.

Excerpt 2 shows that the PSTs valued the opportunity to observe their peers interpreting, through teaching, the learning they had all engaged in, in University based workshops, in a classroom with 'actual' students. An implication here is that, whilst the PSTs have many opportunities to discuss and clarify their thinking in University workshops, the opportunity to actually see each other teach provides an insight that is not possible through discussion only.

3. Mimicking the structure of how planning is done in schools I think this was a valuable team experience. Sharing of ideas made the unit more diverse and interesting.

The PST shares their view, in excerpt 3, that through planning and teaching within PLCs reinforced by technology supported peer observation, the process was a more authentic and faithful representation of what they believe will occur in their working life as a teacher.

4. Great opportunity to teach a sequence of lessons to students and have feedback from peers and lecturers. Liked working collaboratively as everyone brought ideas to the table which were critically reviewed so on the whole lessons were at a high standard.

The PST reflects in excerpt 4 , that the process of peer observation and feedback was a very positive experience. They share their view that the opportunity resulted in overall high quality lessons being planned and taught. It is interesting that the process of their teaching and planning being 'critically reviewed' was seen as a positive, where this could easily be perceived in a negative way.

5. I feel far more confident in the teaching of STEM units. My knowledge background was strong and I was confident I knew the concepts very well. My experiences here have now given me the ability to know how to apply my knowledge and transfer the desired understandings to my students. Scaffolding their achievement of success criteria is achieved by designing appropriate activities and lessons that are hands on, engaging, student-led, and also, highly enjoyable and fun. 
The PST, in excerpt 5, suggests that whilst their content knowledge in the various disciplines of STEM was strong, the process of engaging within the PLC and providing and receiving feedback through peer observation, strengthened their pedagogical content knowledge. This aligns with data collected, reported in the following sub section, suggesting that feedback was focused more on pedagogical approaches, than specific content in the STEM disciplines.

6. It has been the most constructive process of science teaching I have experienced in the entire MTeach course. The feedback has been excellent over the course to allow us to refine and develop the lessons.

PSTs, prior to engaging in the STEM elective, had not had the opportunity to observe each other teach or provide and receive feedback from each other on their teaching. Comments from the PST in excerpt 6, indicate that this was a very useful component of the elective. PSTs have received feedback and critiques of their teaching throughout the course from University academic staff and mentor teachers, in addition to a range of anecdotal feedback. Excerpts, suggest that the PSTs at times, value the feedback from their peers as more meaningful than from individuals who they would consider to be assessing and judging them.

\subsection{PST Focusses of peer feedback}

Table 1 shows how PSTs focused their peer feedback within Padlet. It is clear that 'Engineering' and 'Technology' was not a focus of the teaching nor of feedback. This can largely be explained. As previously stated, in the year that this data was gathered the context for teaching was 'Bees and Bee Adaptations'. Whilst subsequent and previous years of the elective involved a greater focus on these disciplines, this context did not lend itself well to exploration and investigation with Engineering and Technology. Interestingly, the data shows that PSTs were by far and away most concerned with focusing their peer feedback on general pedagogical issues; providing 204 contributions with this as a focus. The next closest, Mathematics, received 66 contributions.

It was of interest to observe that whilst only marginally, Mathematics was a greater focus of PST feedback than Science. Given, the Scientific nature of the context of this inquiry, we had anticipated that Science would be a greater focus during these discussions. Additionally, some researchers in the field of STEM education claim that Mathematics can often be overshadowed when working in a STEM context [18]. They suggest, that Science can be considered the 'dominant' discipline within the term. Data collected here, suggests that when working to develop and teach STEM based inquiry learning, Mathematics, if anything was of marginally greater an emphasis.

Table 1: Padlet Derived feedback by PSTs by Discipline

\begin{tabular}{lcccc}
\hline & Group A & Group B & Group C & Total \\
\hline Engineering & 0 & 0 & 0 & 0 \\
General Pedagogy & 60 & 51 & 93 & 204 \\
Mathematics & 37 & 21 & 8 & 66 \\
Science & 19 & 11 & 25 & 55 \\
STEM & 6 & 1 & 5 & 12 \\
Technology & 0 & 2 & 0 & 2 \\
\hline
\end{tabular}


Table 2 provides insight into how PSTs' focus of feedback changed throughout the 4-week teaching sequence. Whilst, there were a greater number of overall Mathematics focused contributions compared to Science based contributions, no contributions were focused within the area of Mathematics in Week 1. We hypothesize that the scientific context of the teaching sequence was central to 'setting the scene' for the investigation. Further evidence for our hypothesis, relates to Science related feedback being in greatest evidence in the initial two weeks of the sequence.

Table 2: Focus of peer feedback from Padlet

\begin{tabular}{lcccc}
\hline & Week 1 & Week 2 & Week 3 & Week 4 \\
\hline Engineering & 0 & 0 & 0 & 0 \\
General Pedagogy & 59 & 45 & 48 & 52 \\
Mathematics & 0 & 14 & 36 & 16 \\
Science & 13 & 19 & 6 & 17 \\
STEM & 3 & 1 & 3 & 5 \\
Technology & 0 & 0 & 0 & 2 \\
\hline
\end{tabular}

\section{Conclusions and Implications}

Underpinning and supporting the peer observation process was a CSCL environment (Padlet) accessed through mobile technologies. A number of features were essential for mobile technologies to support PST feedback. These included, equality of contribution. All participants also had equal ability and agency to contribute through their personal device. PSTs had multiple opportunities to contribute. Unlike face to face feedback, they could build on and develop their feedback over the course of the lessons. They had the opportunity to edit and modify their own contributions making the process more fluid and dynamic. It is believed that the use of mobile technologies enhanced the metacognitive practices of the observers. In addition to having the ability to edit their own contributions, PSTs built on other PSTs contributions, allowing them to recognize aspects of the teaching process they may not otherwise have considered.

Critics of peer observation within PLCs have argued that the process is easily subverted. They suggest that it is easily manipulated by figures of authority, as an opportunity to ensure compliance and an opportunity to carry out surveillance [9].

Others suggest that staff are not qualified to judge their peers. There remains no definitive agreement about what constitutes the most successful teaching style or method, therefore any judgement or critique of peers, relies on the (peer) assessor's subjective view about what constitutes effective teaching practices [8].

We question how, when teaching at a school or tertiary level, even when a reflective approach to peer observation and feedback is utilized, can the power imbalance between observer and observee be reconciled?

We agree with Shortland [9], that the approach regularly taken to peer observation and feedback that occurs in professional teaching environments, usually only provides a small 'snapshot' of what has occurred throughout a sequence of teaching. Thus, it becomes difficult for an observer to know how the session relates to the rest of the 
program. With this constraint in mind, the quality and value of feedback is compromised.

Despite these reservations, we see mobile technology supported peer observation within PLCs as part of PST education and training as fundamentally different. Our PSTs are enrolled in their course with the purpose of preparing to become primary school teachers. Thus, they are positioned, upon enrolment in their course, as learners.

Survey data, collected as part of this study, indicates that rather than feeling surveilled or viewing the process as an exercise in compliance, PSTs embraced the process as an authentic learning opportunity. Relative, to the potential levels of disempowerment they experience when being observed by academic supervisors and mentor teachers, the process of observing and being observed by their fellow students is liberating, in that all participants in the process are striving to achieve the same goal; becoming the best teacher possible.

Unlike, examples provided in the literature [8, 9, 19], observers were able to view the entire teaching sequence (occurring over 4 weeks). Thus, PSTs were able to see how the sequence unfolded, avoiding issues associated with an observer having a disconnected understanding of how the teaching cohesively came together.

In addition, to gaining an understanding of how our PSTs perceived the process of technology supported peer observation within PLCs, we were interested in how our PSTs would focus the feedback that they posted in the CSCL environment (Padlet). It had been anticipated that the content focus of their feedback may predominantly lie in the area of science, as a result of literature suggesting that mathematics is often overshadowed within a STEM education context [18]. However, as reported, mathematics was of a slightly greater emphasis in PST contributions within the CSCL environment.

It had not been anticipated that the overwhelming majority of feedback would relate to observations and suggestions about general pedagogy. It may be that the PSTs felt more secure and confident offering feedback related to broader pedagogical issues. It is also possible that given that the teaching sequences were collaboratively planned amongst the PST cohort, there was a common understanding of the content being taught, therefore PSTs had less need to focus feedback on content areas. In the moment, pedagogical choices however are not necessarily shared understandings and therefore would compel observers to provide commentary or feedback.

Interestingly, no mathematics centred feedback occurred in the first week of data collection. We have argued that science has provided a context, or a tangible narrative, from which to 'steer' the STEM sequence of learning. Therefore, it is a major focus of feedback in the initial two weeks.

We suggest an implication for the planning of STEM sequences of learning, or for a general framework for STEM units; that science can be considered the 'host domain', from which engagement in the learning is launched.

Mathematics is later utilized within the STEM sequence of learning as a tool for the interrogation and analysis of data, helping to communicate understanding. Neither discipline need be overshadowed. Instead PSTs can be encouraged to achieve balance, utilizing science and mathematics in a purposeful, targeted and synergistic manner. 


\section{References}

1. Griffin, P., McGaw, B., Care, E.: Assessment and teaching of 21st century skills. Springer (2012)

2. Prinsley, R., Baranyai, K.: STEM skills in the workforce: what do employers want. Office of the Chief Scientist, Canberra (2015)

3. Sullivan, P., Tobias, S., McDonough, A.: Perhaps the decision of some students not to engage in learning mathematics in school is deliberate. Educational Studies in Mathematics 62, 81-99 (2006)

4. Martin, A.J., Anderson, J., Bobis, J., Way, J., Vellar, R.: Switching on and switching off in mathematics: An ecological study of future intent and disengagement among middle school students. Journal of Educational Psychology 104, 1 (2012)

5. Stoll, L., Bolam, R., McMahon, A., Wallace, M., Thomas, S.: Professional learning communities: A review of the literature. Journal of educational change 7, 221-258 (2006)

6. Boud, D., Cohen, R., Sampson, J.: Peer learning in higher education: Learning from and with each other. Routledge (2014)

7. Martin, G.A., Double, J.M.: Developing higher education teaching skills through peer observation and collaborative reflection. Innovations in Education and Training International 35, 161-170 (1998)

8. Cosh, J.: Peer observation: a reflective model. ELT journal 53, 22-27 (1999)

9. Shortland, S.: Peer observation: A tool for staff development or compliance? Journal of further and higher education 28, 219-228 (2004)

10. Derrida, J.: Of grammatology. JHU Press (2016)

11. Chaffee, D.: Structuralist and post-structuralist social theory. Routledge (2009)

12. Ciampa, K.: Learning in a mobile age: an investigation of student motivation. Journal of Computer Assisted Learning 30, 82-96 (2014)

13. Ekanayake, S.Y., Wishart, J.: Integrating mobile phones into teaching and learning: A case study of teacher training through professional development workshops. British Journal of Educational Technology 46, 173-189 (2015)

14. Foulger, T.S., Waker, M.L., Burke, D., Hansen, R., Kim Williams, M., Slykhuis, D.A.: Innovators in teacher education: Diffusing mobile technologies in teacher preparation curriculum. Journal of Digital Learning in Teacher Education 30, 21-29 (2013)

15. Symons, D., Pierce, R., Redman, C.: Exploring collaborative online problem solving as opportunity for primary students' development of positive mathematical identity. Australasian Association for Research in Education AARE, Melbourne: Australia (2016)

16. Dillenbourg, P.: What do you mean by collaborative learning? In: Dillenbourg, P. (ed.) Collaborative-learning: Cognitive and computational approaches., pp. 1-19. Elsevier, Oxford (1999)

17. Iksan, Z.H., Nor, S.N.A.M., Mahmud, S.N., Zakaria, E.: Applying the principle of" Lesson study" in teaching science. Asian Social Science 10, 108 (2014)

18. English, L.D.: STEM: Challenges and opportunities for mathematics education. Proceedings of the 39th Conference of the International Group for the Psychology of Mathematics Education, vol. 1, pp. 4-18. PME (2015)

19. Hammersley-Fletcher*, L., Orsmond, P.: Evaluating our peers: is peer observation a meaningful process? Studies in Higher Education 29, 489-503 (2004) 